\title{
Concomitant struma ovarii with serous cystadenoma in a background of tuberculosis: A rare and interesting presentation
}

\author{
Swati Bhardwaj ${ }^{1}$, Surbhi Goyal ${ }^{1}$, Amit Kumar Yadav ${ }^{*}$, Achala Batra ${ }^{2}$ and Ankur Goyal ${ }^{3}$ \\ ${ }^{1}$ Department of Pathology, VMMC and Safdarjung Hospital, New Delhi, India \\ ${ }^{2}$ Department of Obstetrics and Gynaecology, VMMC and Safdarjung Hospital, New Delhi, India \\ ${ }^{3}$ Department of Radiodiagnosis, All India Institute of Medical Sciences, New Delhi, India
}

\begin{abstract}
Struma ovarii is a rare ovarian tumour accounting for less than $5 \%$ of all ovarian neoplasms. It may occur with nongerminal epithelial ovarian neoplasms, but the coexistence of struma ovarii with serous cystadenoma is extremely uncommon with only 6 cases reported so far. Occurrence of these two in a setting of tubercular oophoritis is even rarer, and to the best of our knowledge, this is the first such case. We present a case of a 63-year-old multiparous postmenopausal woman who presented with an ovarian mass. Clinicoradiologically possibility of a neoplastic ovarian cyst was considered. Histopathological examination revealed coexisting triple pathologies; of which struma ovarii in a setting of tuberculosis was an incidental finding. This case is important, not only being rare, but it also highlights the importance of careful and extensive histopathological examination even in a seemingly simple cystic lesion of the ovary to avoid missing concomitant focal pathologies.
\end{abstract}

\section{Introduction}

Struma ovarii is a rare ovarian tumour accounting for less than $5 \%$ of all ovarian neoplasms [1]. It belongs to the group of monodermal teratomas and the term is reserved for only those monodermal teratomas when the proportion of thyroid tissue is more than $50 \%$ of the overall tissue $[2,3]$. Struma ovarii has been found to coexist with other ovarian malignancies, most common being mucinous cystadenoma, followed by Brenner tumour, thecoma, ovarian fibroma, and focal hilus cell hyperplasia. A coexistence of struma ovarii with serous cystadenoma has only been reported in six cases so far [4-7]. Occurrence of these two in a setting of tubercular oophoritis is even rarer and to the best of our knowledge, ours is the first case with such a combination. We report one such interesting case in which triple pathologies were incidentally diagnosed on histopathology.

\section{Case report}

A 63-year-old P4L4 postmenopausal woman presented with the chief complaints of lower abdominal pain and abdominal pain and distension since 3 months. The pain was insidious in onset, dull aching and progressively increasing over 3 months. She was a known diabetic for last 10 years and did not have any other significant past medical or surgical history.

Per abdomen, examination revealed a mass in the pelvis of approximately 18 weeks uterus size. On per vaginum examination, the mass was cystic, and felt to be attached to the uterus on the right side with side-to-side mobility.

Chest X-ray was normal. Ultrasound abdomen showed features suggestive of a large complex right adnexal cystic lesion measuring $16.5 \times 15.8 \times 10.5 \mathrm{~cm}$ with a small solid component. Contrast enhanced computed tomography revealed a well-encapsulated cystic lesion in the lower abdomen and pelvis, separate from the uterus. The mass was extending on both sides of midline and ovaries were not visualized separately. There was a small loculation anteriorly and an eccentric solid enhancing mural nodule hypointense of both T1 and T2 weighted sequences (Figure 1). The tumour markers (CA-125, CEA, AFP) were within normal limits.

A provisional clinical diagnosis of a neoplastic cystic ovarian tumour was made and the patient is taken up for laparotomy. Excision of the mass with hysterectomy and bilateral salpingooopherectomy were done. Per operatively, there were multiple cheesy white nodules over the peritoneum, omentum and serosal surface all over the abdomen. Thus, pelvic lymphadenectomy with infracolic omentectomy and peritoneal biopsy were also performed and sent for histopathological examination.

Grossly, uterus with left side fallopian tube and ovary measured $15 \times 12 \times 3.5 \mathrm{~cm}$. Right ovary was separate and measured $16 \times 15 \times 10 \mathrm{~cm}$. The external surface was pearly white and showed numerous small tubercles varying in size from 0.3 to $0.5 \mathrm{~cm}$ in diameter (Figure 2). On cut, it was a unilocular cyst filled with serous fluid. Multiple cystic solid nodules ranging in size from $1.0-2.5 \mathrm{~cm}$ were seen. On cut, these revealed glistening, gelatinous, greenish brown colloid. Approximately $50 \%$ of the cyst wall was smooth, wrinkled and grayish white in color

Correspondence to: Amit Kumar Yadav MD, Associate Professor, Department of Pathology, Vardhman Mahavir Medical College \& Safdarjung Hospital, New Delhi-110029, India, Tel: +91-011-26707408; E-mail: amityadav7284@yahoo.co.in

Key words: cystadenoma, ovary, serous, struma ovarii, tuberculosis

Received: September 25, 2017; Accepted: October 23, 2017; Published: October 25,2017 


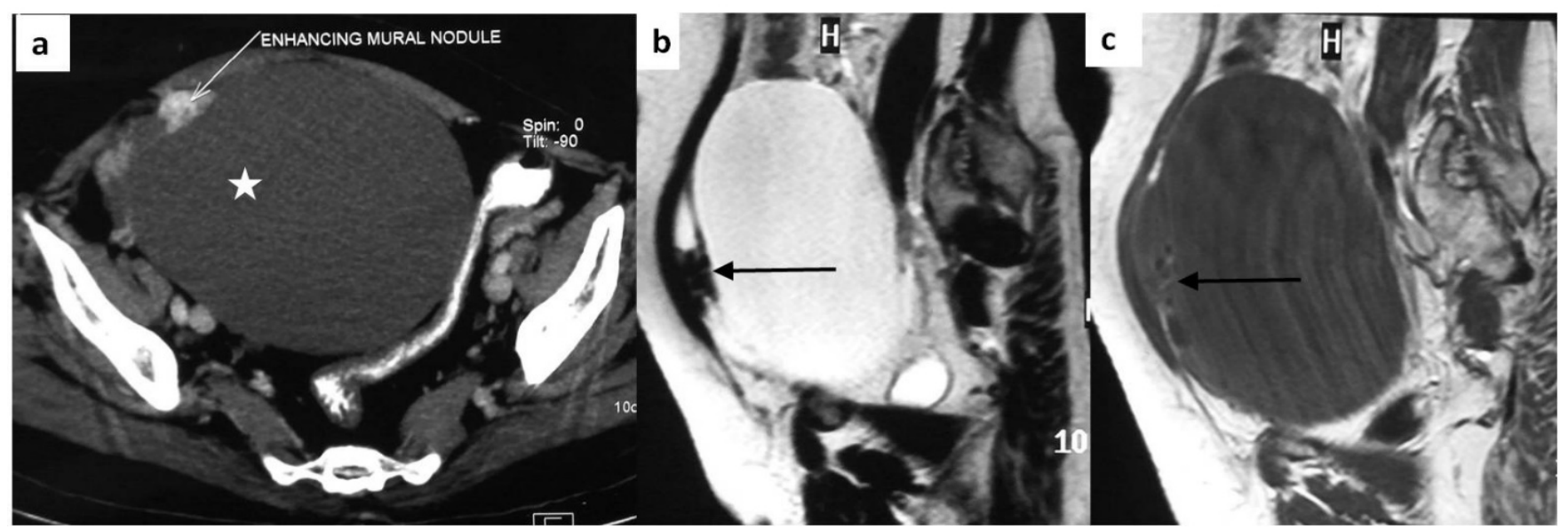

Figure 1. Axial CECT image (a) shows large hypodense cystic lesion in the pelvis (asterisk), separate from the uterus. The lesion is almost entirely cystic with small enhancing eccentric moral nodule (white arrow). Sagittal T2 weighted (b) and T1 weighted (c) MR images confirm the predominant fluid signal intensity of the lesion (T2 hyperintense and T1 hypointense). A small loculation is present anteriorly which shows hypointense solid component (arrows).

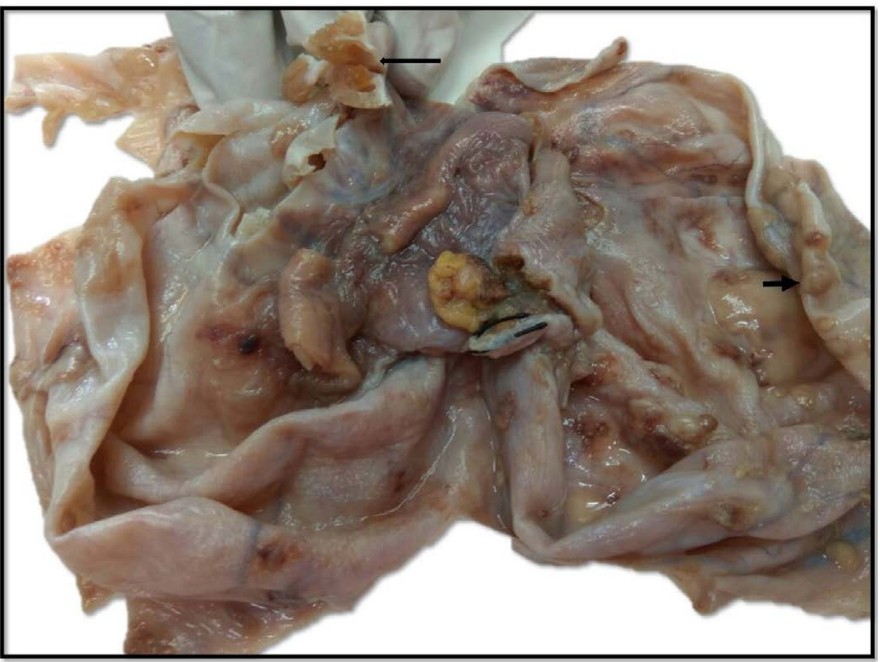

Figure 2. Gross photograph shows outer surface of ovary with attached fallopian tube, and numerous gray white tubercles measuring $0.3-0.6 \mathrm{~cm}$ in diameter (short arrow). Inner surface (turned inwards) shows a glistening tan brown (colloid filled) nodule (long arrow).

without any hair, cartilage or solid area. Histopathological examination from the flat wrinkled areas showed a fibrocollagenous thin cyst lined by ciliated columnar epithelial lining suggestive of a serous cystadenoma (Figure 3a). There was no stratification, nuclear atypia, mitoses, or papillary architecture. Sections from the cystic nodules showed multiple variable sized thyroid follicles (50\%) filled with abundant colloid (Figure 3a). On immunohistochemistry, the follicular cells were positive for thyroid transcription factor-1 (TTF-1), whereas the cyst wall lining was negative (Figure $3 \mathrm{~b}$ ). Extensive sampling was done to look for other germ cell derivatives. However, no other component was identified. Sections from the tubercles showed caseous necrosis (Figure $3 \mathrm{~d}$ ) surrounded by epithelioid cell granulomas (Figure $3 \mathrm{c}$ ). Grossly omentum measured $24 \times 18 \times 1.5 \mathrm{~cm}$ and showed tubercles measuring $0.5-0.8 \mathrm{~cm}$ in diameter. Sections from the pelvic nodes and omentum showed caseous necrosis with granulomatous inflammation. However, stain for AFB was negative. The uterus, fallopian tubes and left ovary were unremarkable. Thus a final diagnosis of concomitant struma ovarii with serous cystadenoma in a background of tubercular oophoritis was rendered.

\section{Discussion}

Struma ovarii are extremely rare ovarian tumours. Approximately 5-15\% of mature cystic teratomas show variable proportion of thyroid tissue; however, proportion of thyroid should be more than $50 \%$ to classify it as struma ovarii [1-3]. Struma ovarii has been reported to coexist with non-germinal epithelial tumors such as mucinous cystadenoma, Brenner's tumor, and rarely serous cystadenofibroma $[4,6]$. However, its association with serous cystadenoma is extremely unusual with only 6 cases reported so far. In a study of 96 cases of struma ovarii, the coexisting serous cystadenoma was found in only 3 cases $(3.1 \%)[4]$.

Grossly, typically the tumor is predominantly solid, with a tan brown glistening appearance. Cystic struma ovarii is extremely rare $[1,2,8]$ which makes its identification difficult [8]. However, the presence of a greenish brown glairy thick fluid can provide a clue to the diagnosis. In our case, the serous lining of the cyst was negative for TTF-1, thus ruling out cystic struma ovarii.

Teratoma is a germ cell neoplasm whereas origin of serous cystadenoma can be explained by metaplasia of the ovarian surface epithelium $[9,10]$. Another possibility could be that the teratoma resulted from the ovum evolved in a graffian follicle, which failed to rupture, and the mucinous cystadenoma (or serous cystadenoma in our case) arose from the 'epithelial metaplasia' of the follicular lining [11]. Owing to the limited number of cases in literature, there is no direct hypothesis to explain this unusual coexistence. Our case and immunohistochemistry findings support the "epithelial metaplasia" hypothesis, similar to the previous case reports [5-7].

Disseminated tuberculosis was an incidental finding in our case, unrelated to the pathogenesis of either of the other two entities. The patient may have had indolent systemic tuberculosis in the setting of which the other two tumours developed. Although tuberculosis is rife in India, however, ovarian tuberculosis per se is relatively uncommon. Two forms of ovarian tuberculosis are known: perioophoritis, in which the ovary is encased in adhesions and studded with tubercles caused by direct extension from the tube; and oophoritis, in which infection spreads via hematogenous route and produces caseating granulomas within the ovarian parenchyma [12]. Ovarian involvement resulting in granulomatous oophoritis in our case can be explained by a hematogenous spread of infection. 
Nevertheless, it is not just an interesting, unusual and diagnostically difficult combination of triple pathologies, but also, a case that highlights the importance of careful and extensive pathological examination even in a seemingly simple cystic lesion of the ovary to avoid missing coexisting focal pathologies.

\section{References}

1. Kondi-Pafiti A, Mavrigiannaki P, Grigoriadis Ch, Kontogianni-Katsarou K, Mellou A, et al. (2011) Monodermal teratomas (struma ovarii). Clinicopathological characteristics of 11 cases and literature review. Eur J Gynaecol Oncol 32: 657-659. [Crossref]

2. Talerman A, Vang R (2011) Germ cell tumors of the ovary. In: Kurman RJ, Hedrick Ellenson L, Brigitte M (Eds.), Blaustein's Pathology of the Female Genital Tract. New York: Springer-Verlag, 847.

3. Mandic A, Tesic M, Rajovic J, Vujkov T, Zivalijevic M, et al. (2001) Ovarian teratomas: Struma ovarii. Arch Oncol 9: 189-91. [Crossref]

4. Wei S, Baloch ZW, LiVolsi VA (2015) Pathology of Struma Ovarii: A Report of 96 Cases. Endocr Pathol 26: 342-348. [Crossref]
5. Terada T (2012) Coexistence of struma ovarii and serous cystadenoma of the ovary. Int J Gynecol Pathol 31: 149-150. [Crossref]

6. Kataria SP, Batra A, Singh G, Boombak E, Sen R, Singh S (2014) Serous cystadenoma associated with cystic struma ovarii: a rare entity. Journal of Gynecologic Surgery 30: 58-60.

7. Rojekar AV, Fernandes GC (2015) A Rare Case Report Of Cystic Struma Ovarii With Co-Existing Serous Cystadenoma. JPGO 3.

8. Szyfelbein WM, Young RH, Scully RE (1995) Struma ovarii simulating ovarian tumors of other types. A report of 30 cases. Am J Surg Pathol 19: 21-29. [Crossref]

9. Tang P, Soukkary S, Kahn E (2003) Mature cystic teratoma of the ovary associated with complete colonic wall and mucinous cystadenoma. Ann Clin Lab Sci 33:465-70. [Crossref]

10. Nomura K (1995) Mucin histochemistry of ovarian mucinous cystadenomas expressing gastrointestinal characteristics. Pathol Int 45:430-35. [Crossref]

11. McKenney JK, Soslow RA, Longacre TA (2008) Ovarian mature teratomas with mucinous epithelial neoplasms: morphologic heterogeneity and association with pseudomyxoma peritonei. Am J Surg Pathol 32: 645-55. [Crossref]

12. Klein TA, Richmond JA, Mishell DR Jr (1976) Pelvic tuberculosis. Obstet Gynecol 48: 99-104. [Crossref]

Copyright: (C2017 Bhardwaj S. This is an open-access article distributed under the terms of the Creative Commons Attribution License, which permits unrestricted use, distribution, and reproduction in any medium, provided the original author and source are credited. 